\title{
Changes in motility, ATP content, morphology and fertilisation capacity during the movement phase of tetraploid Pacific oyster (Crassostrea gigas) sperm
}

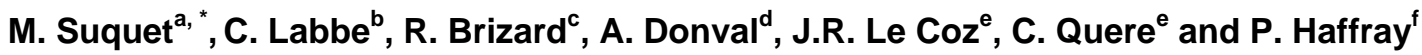 \\ a Ifremer, Station Expérimentale d'Argenton, PFOM Department, 29840 Argenton, France \\ b INRA, UR 1037 SCRIBE, Campus de Beaulieu, 35000 Rennes, France \\ c Ifremer, AGSAE Department, 17390 La Tremblade, France \\ d IUEM, Technopole Brest-Iroise, 29280 Plouzané, France \\ e Ifremer, PFOM Department, 29280 Plouzané, France \\ ${ }^{\dagger}$ SYSAAF, Scribe, Campus de Beaulieu, 35042 Rennes, France \\ *: Corresponding author : M. Suquet, Tel.: +33 2988957 55; fax: +33 2988957 77, email address : \\ Marc.Suquet@ifremer.fr
}

\begin{abstract}
:
Changes in sperm features during the movement phase are especially interesting to study in external fertilization species whose sperm duration movement is long because this implies a significant adaptation of moving cells to the external medium. This study describes the changes in tetraploid Pacific oyster sperm characteristics in relation to time post activation.
\end{abstract}

Sperm individually collected on three tetraploid males were activated in seawater. Their features were analysed over a $24 \mathrm{~h}$ period and compared to a sperm pool collected on three diploid males as a reference. The percentage of motile spermatozoa, the intracellular ATP content, and the fine structure of spermatozoa were studied in relation to time post activation. Furthermore, the fertilisation capacity of sperm individually collected on five diploid males was assessed after 1 and $24 \mathrm{~h}$ post activation.

A forward progressive movement was maintained for at least a $20 \mathrm{~h}$ duration. Compared to diploid males, the percentage of motile spermatozoa was lower in tetraploid males. The intracellular ATP concentration was higher in spermatozoa from tetraploid males than in spermatozoa from diploid males. A decrease in ATP content was observed in the first $6 \mathrm{~h}$ post activation and severe alterations were observed in sperm morphology after $24 \mathrm{~h}$. Then, a lower fertilisation capacity of sperm from diploid males was observed at the end of the movement phase.

The cessation of Pacific oyster sperm motility was unlikely caused by ATP consumption as ATP concentration was still high at the end of sperm movement but rather caused by drastic changes in sperm morphology. Compared to sperm collected on diploid males, the lower quality of sperm from tetraploid males was emphasized by a shorter movement duration and deeper morphological alterations at the end of the movement phase.

Keywords: Crassostrea gigas; Sperm; Tetraploid; Motility; ATP; Ultrastructure 


\section{Introduction}

In aquatic broadcast spawners, spermatozoa are most often immotile in the male reproductive organ. After release, sperm is submitted to the aquatic environmental conditions. Changes in the surrounding environment trigger sperm movement [1] whose duration depends on the reproductive strategy of the species in relation with sperm cellular characteristics.

The changes in sperm features in relation to time after activation have been studied on a few aquatic species and mainly on those whose spermatozoa bear short movement duration. In rainbow trout (Oncorhynchus mykiss) where the cessation of gamete movement is observed $30 \mathrm{~s}$ after sperm release in freshwater, the cellular structure undergoes considerable changes located at the mid piece and at the plasma membrane [2]. A rapid depletion of intracellular ATP content is correlated to the decrease in the percentage of motile spermatozoa [3]. In seabass (Dicentrarchus labrax), the percentage of motile spermatozoa and sperm velocity decrease in relation to time after activation in seawater, over the $40 \mathrm{~s}$ swimming phase. At the end of the movement, sperm head swelling is observed, chromatin appears heterogeneous and intracristae spaces of mitochondria are enlarged [4]. Similar observations are reported for turbot (Psetta maxima) sperm, although the swimming phase lasts longer (3-5 minutes). Contrarily to trout and seabass, a part of the energy required for turbot sperm motility is produced during sperm movement by mitochondrial oxidative phosphorylation [5].

Compared to marine fish species, sperm movement duration is usually longer in marine invertebrates: 4 to 5 hours in Pacific oyster [6] and in American oyster (Crassostrea virginica) [7]. After a 20 hour incubation in seawater, the percentage of motile sea urchin (Hemicentrotus pulcherrinus) spermatozoa is still close to $50 \%$ [8]. Sea urchin (Lytechinus variegatus) sperm velocity and fertilisation capacity decreased as a function of time during a 120 minute period after activation in seawater [9]. In several sea urchin species, after a 30 minute duration movement, changes are observed at the midpiece and especially at the mitochondria level [10]. In Pacific oyster, knowledge on sperm features during the swimming phase is restricted to the reported decrease in the percentage of motile spermatozoa over a 150 minutes post activation period [11].

Triploid molluscs have a higher growth and a lower reproductive capacity than diploid ones [12]. Because they can be obtained by crossing diploid females and tetraploid males [13], standardised procedures for artificial fertilisation using gametes of both ploidies, must be settled. However, sperm features of tetraploid Pacific oysters were little investigated: when compared to sperm collected from diploid males, more than half of the spermatozoa from tetraploid Pacific oysters have a higher mitochondria number [14] although the overall sperm motility is reduced [15].

The broadcast reproductive behaviour of Pacific oysters and sperm dispersion make wild stocks at risk of being genetically contaminated by farmed populations [12]. This is especially the case with tetraploid individuals which have been demonstrated to be fertile in the wild. Fertilisation capacity of these individuals is a function of several biological factors such as sperm characteristics including sperm swimming duration, intracellular ATP content and changes in these features during the movement phase.

In tetraploid males, undergoing the description of sperm features during the movement phase aims to i) improve the knowledge of these singular spermatozoa, ii) help to establish standardised procedures for gamete management and fertilisation which are required for triploid oyster production and iii) explore the risk of genetic contamination of wild stocks by diploid spermatozoa.

In this paper, changes in sperm features of tetraploid Pacific oyster over a 24 hour movement phase are described. The present study wants to address to which extent the characteristics of sperm movement during a long swimming period are different from the known characteristics of sperm with short movement duration, and how these characteristics are related to cellular and energetic parameters supposed to sustain sperm motility. As a consequence, changes in the percentage of motile cells, intracellular ATP content, fine structure as observed by transmission electronic microscopy and fertilisation capacity in 
relation to time post activation are reported. Sperm from diploid males was also studied as a reference.

\section{Materials and methods}

\subsection{Oyster conditioning and gamete stripping}

Tetraploid (one year old) and diploid (three year old) Pacific oyster were conditioned (200L tanks, $\mathrm{T}^{\circ}=19^{\circ} \mathrm{C}$ and fed at $2 \%$ (dry mass of algae to oyster) with two microalgae, Isochrysis galbana Tahitian clone and Chaetoceros gracilis). For both sexes, gametes were obtained according to [16]. After gonad mincing and gamete release, male and female gametes were stored respectively in $4 \mathrm{ml}$ salt immobilising solution "Store-gigas" [16] at $4^{\circ} \mathrm{C}$ and in $2 \mathrm{~L}$ seawater at $19^{\circ} \mathrm{C}$. Sperm concentration was determined in duplicates by image analysis $\left(\right.$ Samba Technologies, Tribvn ${ }^{\circledR}$ ) after dilution of $10 \mu$ l sperm samples in $10 \mu l$ formaldehyde and $1980 \mu$ l salt solution "Store-gigas".

Sperm concentration was adjusted to $2 \times 10^{9}$ spermatozoa/ml by dilution in seawater. Sperm movement was triggered by adding $1 \mathrm{ml}$ of sperm suspension to $4 \mathrm{ml}$ seawater at $20^{\circ} \mathrm{C}$ in $30 \mathrm{ml}$ bottles (final dilution rate: $1: 20$ ). In order to avoid bacterial proliferation during the $24 \mathrm{~h}$ swimming period, chloramphenicol was added at a final concentration of $25 \mu \mathrm{g} / \mathrm{mL}$ (mother solution: $5 \mathrm{mg}$ chloramphenicol $/ \mathrm{ml}$ ethanol). Changes in sperm features were studied by sampling both tetraploid and diploid oyster sperm samples (three individual sperm samples for tetraploid males and a pool collected from three diploid males) at different time post activation. However, the fertilisation capacity in relation to time after sperm activation was only studied in diploid animals ( $\mathrm{n}=5$ oysters).

\subsection{Experimental design}

Sperm motility was estimated at $0,1,6,14,20$ and 24 hours post activation using a two-step dilution procedure: for each sampling, $40 \mu \mathrm{l}$ of the sperm suspension was first diluted with 960 $\mu \mathrm{l}$ activating solution "Moti-gigas" [16]. Then, $5 \mu \mathrm{l}$ of this sperm suspension was transferred to $95 \mu l$ "Moti gigas" (final dilution 1:500). The percentage of motile spermatozoa (sperm with progressive motility) was assessed in triplicates using a dark-field microscope.

Intracellular ATP content was assessed in triplicates, at 0, 1, 6, 14 and 24 hours post activation, by high-performance liquid chromatography analysis as previously described [5]. The fine structure of spermatozoa was studied at 0 and 24 hours post activation in seawater, according to methods previously described in turbot [5]. However, the osmolality of fixative and washing buffers was adjusted to $1000 \mathrm{mosmol} / \mathrm{kg}$ by addition of $\mathrm{NaCl}$. Ultrathin sections were examined with a JEOL TEM $100 \mathrm{CX}$. The following measurements were determined according to [14]: length and width of sperm head and acrosome and length of mitochondria. Furthermore, subacrosomal space dimensions (length and width) were recorded.

The fertilisation capacity of spermatozoa from five diploid males was determined in triplicates after 1 and 24 hours post activation in seawater, according to a standardised experimental protocol [16], using 400 spermatozoa for one egg. Briefly, oocytes were pooled from three females and their concentration was determined by microscopic count $(3 * 50 \mu l)$. Two different spawns were used at 1 and 24 hours post activation. Their fertilisation capacity, as observed using a pool of fresh sperm collected in two males, was not significantly different. The D-larval yield was estimated after 48 hour development at $19^{\circ} \mathrm{C}$ (number of D-larvae/total number of oocytes). 


\subsection{Data analysis}

Data were arcsin square-root transformed prior to two way analysis of variance. When significant differences were observed, a Tukey a posteriori test was used.

\section{Results}

Just after activation, the percentage of motile spermatozoa was high in tetraploid males and showed a progressive reduction during the 24 hour swimming phase (Fig. 1). Compared to diploid ones, the percentage of motile cells was lower $(P<0.001)$ in tetraploid males.

A decrease in ATP content was observed in the first six hours after activation $(P<0.001)$. From 6 to 24 hours post activation, variations of ATP concentration were also observed $(P<0.001)$ but these changes remain limited compared to those observed during the first six hours (Fig. 2). The ATP concentration of sperm from tetraploid males was higher $(P<0.001)$ than that of sperm from diploid males.

At the beginning of the movement phase, the morphology of sperm from tetraploid males was similar to that of sperm from diploid males (Fig. 3a, b and e) except for usual differences known to exist between the two types of spermatozoa: five mitochondria were observed in sperm collected in tetraploid males and four in diploid ones. Linear dimensions of sperm from tetraploid males (height and width of acrosome, head and subacrosomal space) were larger than those of diploid males (Table 1). On the other hand, no difference was observed for the height of mitochondria and for the ratios calculated with the different sperm dimensions.

After a 24 hour movement phase, several morphological alterations were observed in sperm from tetraploid males (Fig. 3d). The plasma membrane became swollen and detached from the sperm head. Vacuoles developed in the nucleus. In some cases, chromatin was deeply decondensed. In general, more drastic morphological changes were observed in sperm collected on tetraploid (Fig. 3d) males than on diploid (Fig. 3c) ones. However, the $24 \mathrm{~h}$ movement phase did not alter the overall mitochondria shape and structure. Acrosome reaction was rarely observed both in diploid (Fig. 3f) and tetraploid males (Fig. 3g). Sperm dimensions were not changed after the 24 hour movement whatever the sperm ploidy. However, the head width was significantly larger at the end of the movement than at the beginning of this phase in sperm from tetraploid males (Table 1 ).

After a 24 hour swimming phase, a lower fertilisation capacity $(P<0.001)$ of sperm collected in diploid oysters was observed compared to results recorded for sperm which moved for one hour (Fig. 4). The fertilisation capacity of male 4 was lower than that recorded in other males $(P<0.05)$.

\section{Discussion}

Basic features of sperm biology remain poorly described in Pacific oyster. In particular, changes in sperm features during the swimming phase have not been reported in the scientific literature. The description of these changes is especially interesting in species whose movement duration is long (a few hours) compared to the short duration of sperm movement recorded in fish species (from $30 \mathrm{~s}$ in rainbow trout [2] to 3-5 minutes in turbot [5]) for which these changes were previously described. A long movement duration suggests a specific adaptation of spermatozoa to the external medium. For farmed broodstock, this prolonged mouvement of spermatozoa increases the risk of genetic pollution in the wild. This is why tetraploid oysters must be maintained in closed recirculated systems equipped with effluent treatment devices in order to prevent the dissemination of their gametes [12]. 
The present work confirms the long duration of the sperm swimming phase already reported in Pacific oyster [6], although a forward progressive movement observed for a 20 hour period had never been described in this species for sperm from tetraploid males. In accordance with the observation of Dong et al. [17], the present results showed that the percentage of motile spermatozoa is significantly lower in tetraploid males compared to diploid ones. This lower performance of spermatozoa in tetraploids was further demonstrated by Suquet et al. [18], who showed that 5000 spermatozoa per oocyte are required in tetraploid males to obtain a maximum fertilisation rate, compared to 500 in diploid males, suggesting a lower fertilisation capacity of sperm from tetraploid males. The lower quality of sperm collected on tetraploid males compared to diploid ones may be due to ploidy but also to differences in rearing environments. Indeed in our conditions, tetraploid males were maintained all year-round in hatchery while diploid ones were transferred from the wild to the hatchery two month before the spawning period.

Just before the swimming phase, the mean ATP content of sperm collected on tetraploid oysters $\left(71.2 \pm 3.1 \mathrm{nmol} / 10^{9}\right.$ spermatozoa) was higher than that of sperm from diploid males $\left(44.7 \pm 2.0 \mathrm{nmol} / 10^{9}\right.$ spermatozoa). The lack of data on sperm ATP content of tetraploid males in other aquatic species makes interspecies comparisons possible only for sperm from diploid males: the ATP levels observed in our conditions before the sperm swimming phase, are similar to those measured in several fish species with shorter movement duration, where intial ATP levels range from 18 to $233 \mathrm{nmol} / 10^{9}$ spermatozoa [19] and are higher than the levels assessed in two sea urchin species (Arbacia lixula and Paracentrotus lividus: 3.9 to 6.2 $\mathrm{nmol} / 10^{9}$ spermatozoa) [20]. This interspecies diversity in ATP levels prevents any relationship to be established between initial ATP level assessed before sperm activation and sperm movement duration. This suggests that initial ATP content of oyster spermatozoa is therefore not the main parameter responsible for the distinctive ability of these cells to sustain such long movement duration.

After a one hour movement, ATP hydrolysis of Pacific oyster sperm was limited since ATP losses represented only $15 \pm 7 \%$ of the initial content. In two sea urchin species, ATP hydrolysis was 54 to $79 \%$ of their initial ATP content, 5 minutes after sperm activation in seawater [20]. Spermatozoa of sea urchin (Hemicentrotus pulcherrimus) exhausted almost $70 \%$ of their initial ATP stores after 10 minutes of movement [21]. This high ATP consumption was also reported in the sea urchin, Anthocidaris crassispina, where $36 \%$ of the initial stores were hydrolysed after a 5 minutes sperm movement at $0^{\circ} \mathrm{C}$ and $73 \%$ at $20^{\circ} \mathrm{C}$ [22]. ATP catabolism of marine fish sperm is also fast: spermatozoa exhausted $74 \%$ of their initial ATP store after one minute of movement in turbot [5].

Later on, during a period ranging from 6 hour to 24 hours post activation, no further decrease in ATP concentration of Pacific oyster sperm was observed. Such maintenance in ATP concentration after the first 6 hours suggests that spermatozoa could partially restore the energy stores catabolised during the motility phase. During the swimming phase of turbot sperm, the mitochondrial oxidative phosphorylation partly compensates for ATP hydrolysis [5]. An increased oxygen consumption was reported after sperm movement activation in sea urchin sperm [20]. This also suggests energy restoration during the swimming phase. In Pacific oyster, no apparent changes of mitochondria were observed at the end of the movement phase, contributing to the high ATP content of sperm assessed after 24 hours. The rationale for ATP level maintenance during the swimming phase of Pacific oyster sperm could be further explored by respiration studies.

The cessation of Pacific oyster sperm motility after 24 hour was unlikely caused by a low concentration of ATP. Between 6 and 24 hours post activation, we observed a discrepancy between the drastic losses of sperm motility percentages (from $47.5 \pm 17.5 \%$ to $3.8 \pm 6.4 \%$ ) and the absence of decrease in ATP content (from $47.1 \pm 6.1$ to $50.5 \pm 6.2 \mathrm{nmol} / 10^{9}$ spermatozoa). Furthermore, 70 to $79 \%$ (in tetraploid males) and $94 \%$ (in diploid males) of the initial ATP stores were still observed after a 24 hour movement.

In accordance with Dong et al. [14], we showed that the general ultrastructure of sperm from diploid and tetraploid males is similar, and that sperm dimensions are different. In the present work, sperm components of tetraploid males were 1.10 to 1.35 times larger compared to those 
assessed in diploid males, close to values observed by Dong et al. : 1.23 to 1.43 [14]. We calculated from [23] that sperm collected in mussels (Mytilus galloprovincialis) tetraploid males were also 1.10 to 1.50 larger than sperm from diploid ones. At the end of the swimming phase, drastic damages were observed in Pacific oyster sperm morphology as reported in other species such as turbot [5]. Deeper damages in chromatin and plasma membrane were observed in sperm from Pacific oyster tetraploid males compared to diploid ones.

Because of the low ATP exhaustion during sperm movement, the drastic changes in morphology of spermatozoa observed after a 24 hour swimming phase, are probably the cause of the cessation of sperm movement. Alternative hypothesis of sperm movement cessation such as the lack of ATP-shuttle molecules, observed in sea urchin spermatozoa [24] and transporting energy from mitochondria to the axoneme, can also be suggested. The causes of sperm movement cessation would be further explored by describing the capacity of spermatozoa to perform a second swimming phase after incubation in a non activating medium.

Our work showed a drastic decrease in the fertilisation capacity of Pacific oyster sperm at the end of the swimming phase, likely because of the low percentage of motile sperm. The fertilisation capacity of turbot and seabass sperm also decreased at the end of their movement phase, as a consequence of the low percentage of motile spermatozoa [25]. A relationship between time after sperm activation, and the fertilisation success was also reported in sea urchin (Strongylocentrotus franciscanus) [26].

As a conclusion, the significant adaptation of Pacific oyster spermatozoa to seawater is sustained by a long duration movement and a high ATP content observed at the end of the swimming phase. The cessation of Pacific oyster sperm motility cannot be explained by a too low ATP concentration assessed at the end of sperm swimming phase but rather by drastic changes in sperm morphology, except in sperm dimensions. Compared to sperm collected in diploid males, the lower quality of sperm from tetraploid ones is suggested by a lower movement duration and deeper morphological alterations at the end of the movement phase.

\section{Acknowledgments}

This work was supported by Ofimer (Triplofimer, 052/05/C). We acknowledge C. Mingant, I. Quéau and L. Lebrun (Ifremer) for technical assistance but also A. Benabdelmouna and C. Ledu for tetraploid oyster providing. We want to thank M. Briand (IUEM) for electron micrographs and J. Moal (Ifremer) for fruitful discussions on sperm energetic. 


\section{Figures}

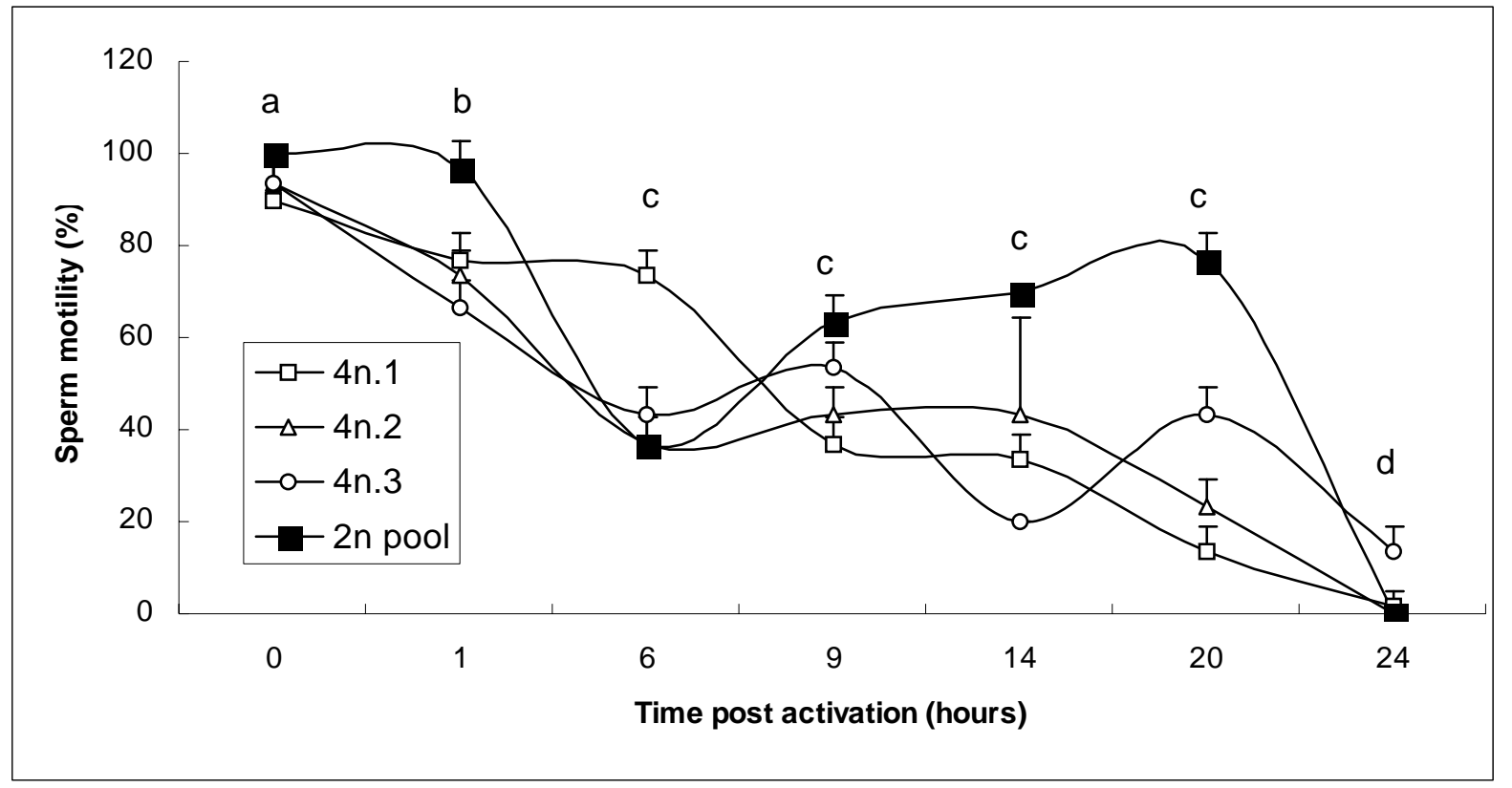

Fig.1. Changes in the percentage of motile spermatozoa in relation to time post activation (mean $\pm S D$; different letters refer to significantly different results versus time). 


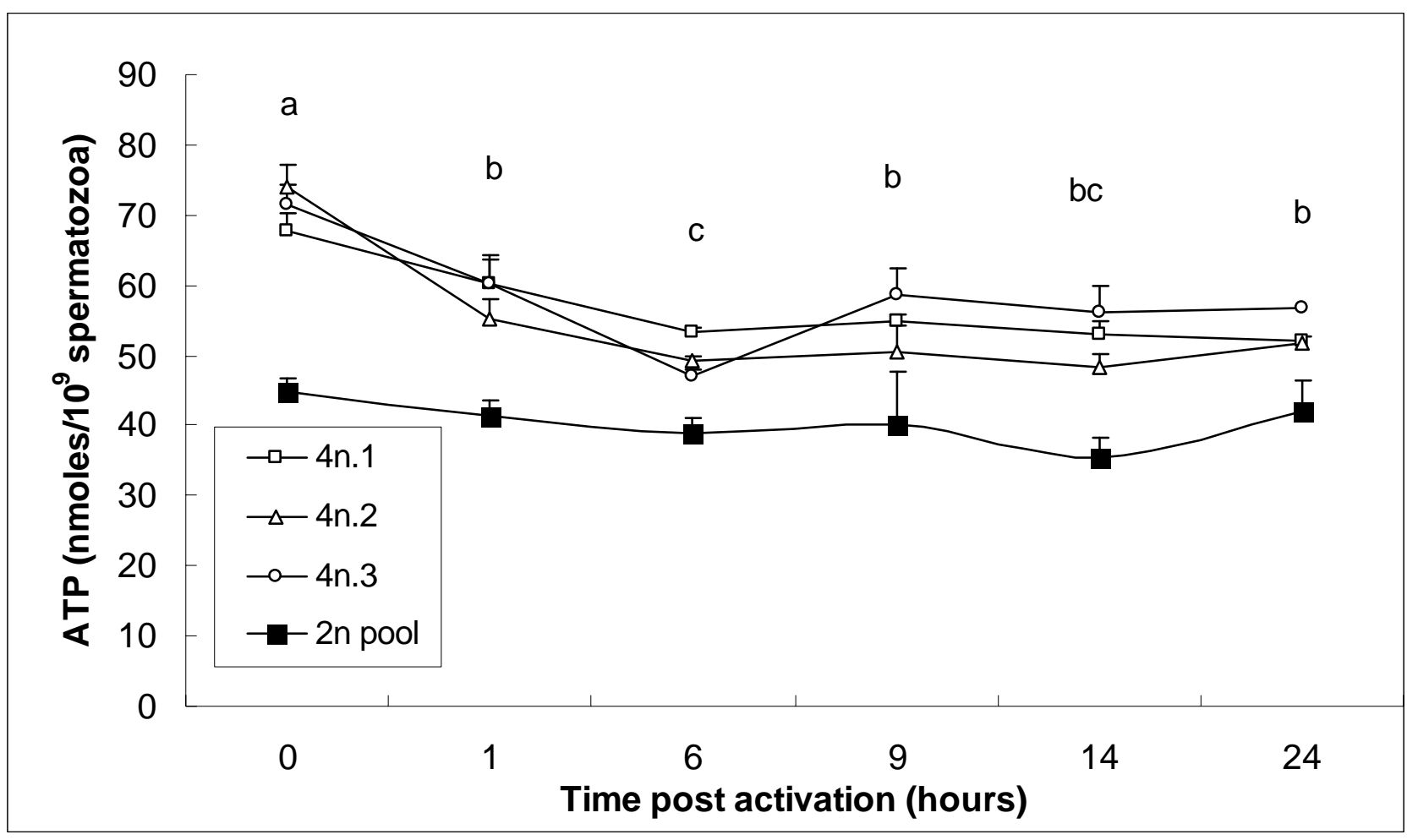

Fig.2. Changes in ATP concentration of spermatozoa in relation to time post activation (mean $\pm S D$; different letters refer to significantly different results versus time). 

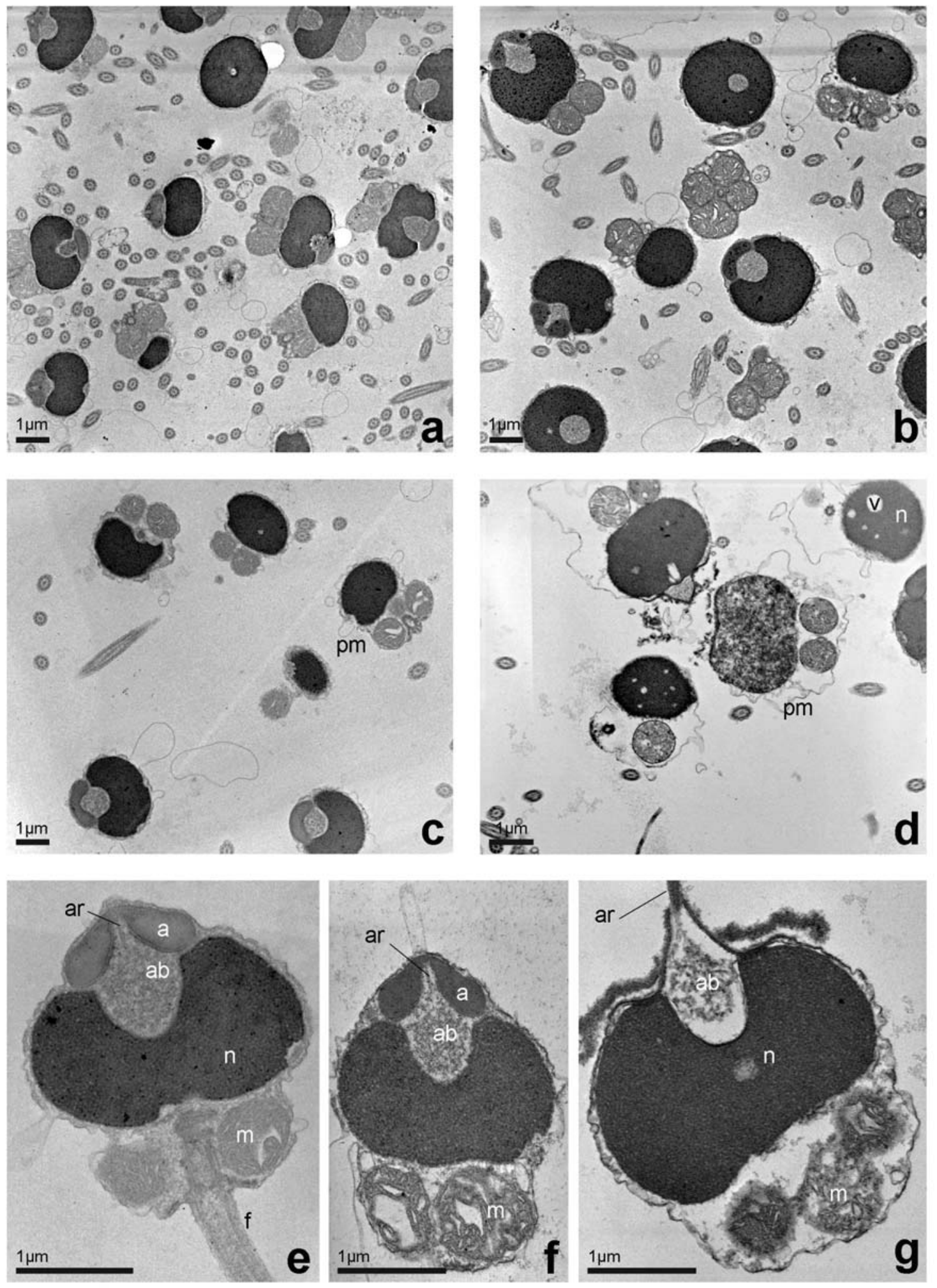

Fig.3. Electron micrographs of Pacific oyster spermatozoa from diploid and tetraploid males, before and after activation. (a) General view of spermatozoa from diploid Pacific oyster before activation. (b) General view of spermatozoa from tetraploid Pacific oyster before activation. (c) General view of spermatozoa from diploid oyster, 24h after activation. (d) General view of spermatozoa from tetraploid oyster, $24 \mathrm{~h}$ after activation; $\mathrm{n}$ : nucleus, pm: plasmic membrane, v: vacuoles. (e) Longitudinal section of a spermatozoon from a diploid male, before activation. (f) Longitudinal section of a spermatozoon from a diploid male at the end of the movement phase and displaying the acrosomial reaction. (g) Longitudinal section of a spermatozoon collected in a tetraploid male at the end of the movement phase and displaying the acrosomial reaction; a: acrosome, ab: axial body, ar: axial rod, $\mathrm{n}$, nucleus, m: mitochondria. 


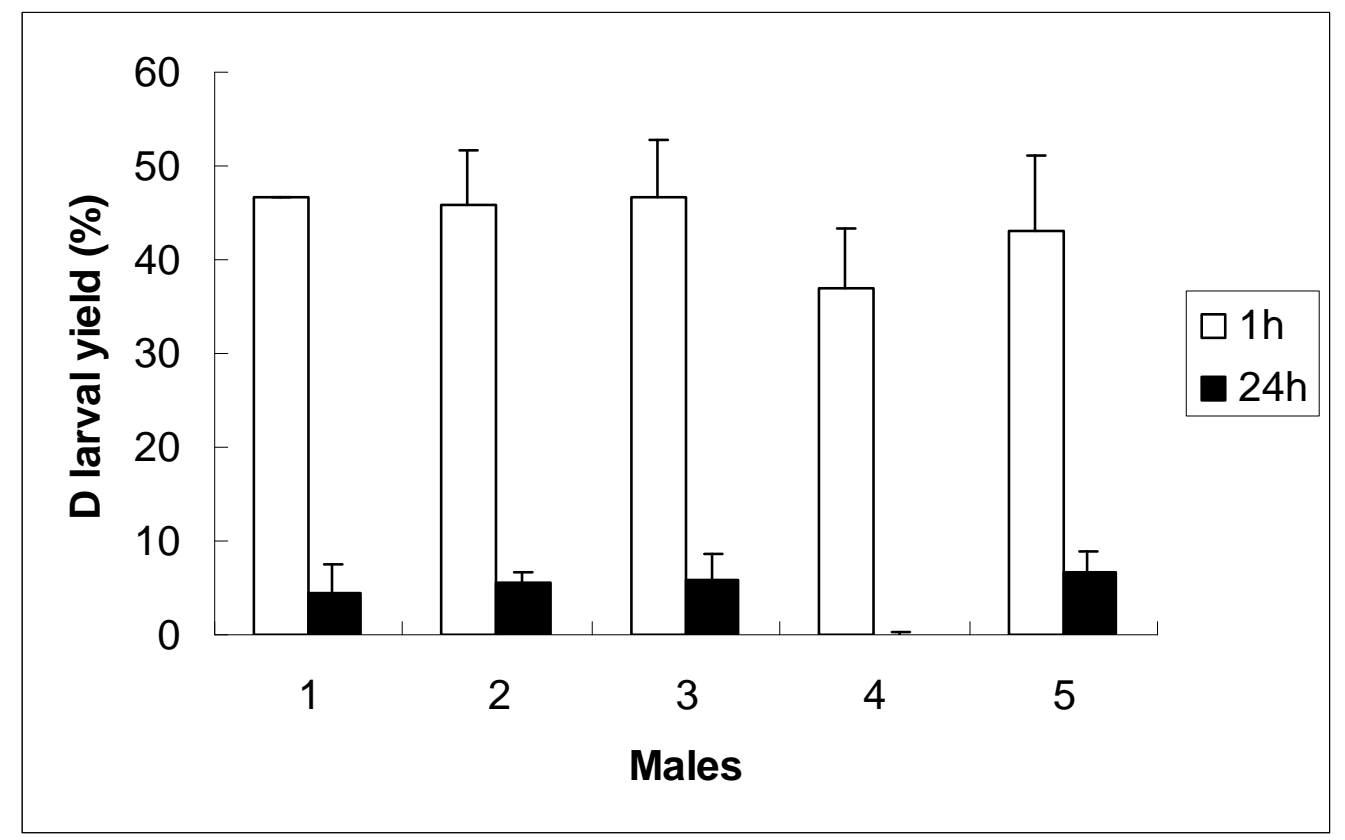

Fig. 4. Changes in fertilisation capacity of sperm from diploid males, at the beginning and at the end of sperm movement phase (mean $\pm S D$; different letters refer to significantly different results).

\section{Tables}

Table 1.

Size $(\mu \mathrm{m})$ and ratios of sperm from $2 n$ and $4 n$ oysters before $(0 h)$ and after $(24 h)$ the movement phase. Different letters refer to significantly different results within rows, $\mathrm{P}<0.001$ (number in brackets indicate the sampling size).

\begin{tabular}{|l|l|l|l|l|l|}
\hline & Parameter & Diploid & Diploid & Tetraploid & Tetraploid \\
\hline & & $\mathbf{0 ~ h}$ & $\mathbf{2 4} \mathbf{h}$ & $\mathbf{0 ~ h}$ & $\mathbf{2 4} \mathbf{h}$ \\
\hline Acrosome & Height & $0.44 \pm 0.13^{\mathrm{a}}(21)$ & $\begin{array}{l}0.46 \pm 0.13^{\mathrm{a}} \\
(22)\end{array}$ & $\begin{array}{l}0.63 \pm 0.12^{\mathrm{b}} \\
(8)\end{array}$ & $0.64 \pm 0.09^{\mathrm{b}}(8)$ \\
\hline & Width & $0.96 \pm 0.13^{\mathrm{a}}(22)$ & $\begin{array}{l}0.93 \pm 0.17^{\mathrm{a}} \\
(23)\end{array}$ & $\begin{array}{l}1.28 \pm 0.10^{\mathrm{b}} \\
(8)\end{array}$ & $1.29 \pm 0.08^{\mathrm{b}}(8)$ \\
\hline & Height/Width & $0.44 \pm 0.14^{\mathrm{a}}(22)$ & $\begin{array}{l}0.50 \pm 0.14^{\mathrm{a}} \\
(21)\end{array}$ & $\begin{array}{l}0.47 \pm 0.06^{\mathrm{a}} \\
(6)\end{array}$ & $0.50 \pm 0.04^{\mathrm{a}}(8)$ \\
\hline Head & Length & $2.59 \pm 0.26^{\mathrm{a}}(21)$ & $\begin{array}{l}2.64 \pm 0.26^{\mathrm{a}} \\
(21)\end{array}$ & $\begin{array}{l}3.27 \pm 0.15^{\mathrm{b}} \\
(5)\end{array}$ & $3.37 \pm 0.26^{\mathrm{b}}(9)$ \\
\hline & Width & $2.14 \pm 0.14^{\mathrm{a}}(22)$ & $2.21 \pm 0.27^{\mathrm{a}}$ & $2.65 \pm 0.18^{\mathrm{b}}$ & $3.06 \pm 0.3^{\mathrm{c}}(12)$ \\
\hline
\end{tabular}




\begin{tabular}{|c|c|c|c|c|c|}
\hline & Parameter & Diploid & Diploid & Tetraploid & Tetraploid \\
\hline & & $\mathbf{O} \mathbf{h}$ & $24 \mathrm{~h}$ & $\mathbf{O} \mathbf{h}$ & $24 \mathrm{~h}$ \\
\hline & & & (23) & (7) & \\
\hline & Length/Width & $1.22 \pm 0.55^{\mathrm{a}}(20)$ & $\begin{array}{l}1.26 \pm 0.20^{\mathrm{a}} \\
(20)\end{array}$ & $\begin{array}{l}1.22 \pm 0.11^{\mathrm{a}} \\
(5)\end{array}$ & $1.09 \pm 0.13^{\mathrm{a}}(9)$ \\
\hline \multirow[t]{3}{*}{$\begin{array}{l}\text { Subacroso } \\
\text { mal space }\end{array}$} & Length & $0.77 \pm 0.16^{\mathrm{a}}(22)$ & $\begin{array}{l}0.79 \pm 0.24^{\mathrm{a}} \\
(23)\end{array}$ & $\begin{array}{l}1.00 \pm 0.15^{\mathrm{b}} \\
(9)\end{array}$ & $1.00 \pm 0.22^{\mathrm{b}}(9)$ \\
\hline & Width & $0.66 \pm 0.09^{\mathrm{a}}(21)$ & $\begin{array}{l}0.67 \pm 0.13^{\mathrm{a}} \\
(21)\end{array}$ & $\begin{array}{l}0.87 \pm 0.06^{\mathrm{b}} \\
(9)\end{array}$ & $0.90 \pm 0.08^{\mathrm{b}}(8)$ \\
\hline & Length/Width & $1.19 \pm 0.20^{\mathrm{a}}(21)$ & $\begin{array}{l}1.28 \pm 0.33^{\mathrm{a}} \\
(21)\end{array}$ & $\begin{array}{l}1.16 \pm 0.22^{\mathrm{a}} \\
(7)\end{array}$ & $1.12 \pm 0.26^{\mathrm{a}}(8)$ \\
\hline $\begin{array}{l}\text { Mitochon } \\
\text { dria }\end{array}$ & Height & $0.87 \pm 0.14^{\mathrm{a}}(29)$ & $\begin{array}{l}0.80 \pm 0.14^{\mathrm{a}} \\
(26)\end{array}$ & $\begin{array}{l}0.90 \pm 0.21^{\mathrm{a}} \\
(7)\end{array}$ & $\begin{array}{l}0.88 \pm 0.11^{\mathrm{a}} \\
(15)\end{array}$ \\
\hline Acrosome & $\begin{array}{l}\text { Height/Head } \\
\text { length }\end{array}$ & $0.17 \pm 0.04^{\mathrm{a}}(20)$ & $\begin{array}{l}0.17 \pm 0.04^{\mathrm{a}} \\
(19)\end{array}$ & $\begin{array}{l}0.18 \pm 0.02^{a} \\
(5)\end{array}$ & $0.19 \pm 0.03^{\mathrm{a}}(6)$ \\
\hline Acrosome & $\begin{array}{l}\text { Width/Head } \\
\text { width }\end{array}$ & $0.45 \pm 0.07^{\mathrm{a}}(22)$ & $\begin{array}{l}0.42 \pm 0.07^{\mathrm{a}} \\
(23)\end{array}$ & $\begin{array}{l}0.47 \pm 0.04^{\mathrm{a}} \\
(5)\end{array}$ & $0.44 \pm 0.05^{\mathrm{a}}(6)$ \\
\hline
\end{tabular}

\section{References}

[1] Cosson J, Groison AL, Suquet M, Fauvel C, Dreanno C, Billard R. Marine fish spermatozoa : racing ephemeral swimmers. Reproduction 2008;136:277-294.

[2] Billard R. Ultrastructure of trout spermatozoa: changes after dilution and deep freezing. Cell Tissue Res 1983;228:205-218.

[3] Christen R, Gatti JL, Billard R. Trout sperm motility. The transient movement of trout sperm is related to changes in the concentration of ATP following the activation of the flagellar movement. Eur J Biochem 1987;166:667-671.

[4] Dreanno C, Cosson J, Suquet M, Cibert C, Fauvel C, Dorange G, Billard R. Effects of osmolality, morphology perturbations and intracellular nucleotide content during the movement of sea bass (Dicentrarchus labrax) spermatozoa. J Reprod Fertil 1999;116: 113-125.

[5] Dreanno C, Cosson J, Suquet M, Seguin F, Dorange G, Billard R. Nucleotide content, oxidative phosphorylation, morphology and fertilizing capacity of turbot (Psetta maxima) spermatozoa during the motility period. Mol Reprod Develop 1998;53:230-243.

[6] Faure C. Paramètres physiologiques de l'émission et de l'activation des gamètes mâles de deux mollusques bivalves : la coquille Saint Jacques Pecten maximus (L.) et l'huître creuse

Crassostrea gigas (Thunberg). Thesis. University of Paris 7,1996,255pp.

[7] Galtsoff PS. The American oyster, Crassostrea virginica Gmelin. Fishery Bulletin of the Fish and Wildlife, US Government printing office, Washington, 1964,64, pp. 324-350.

[8] Ohtake T, Mita M, Fujiwara A, Tazawa E, Yasumasu I. Degeneration of respiratory system in sea urchin spermatozoa during incubation in seawater for long duration. Zool Sci $196 ; 13: 857-863$ 
[9] Levitan R. Sperm velocity and longevity trade off each other and influence fertilization in the sea urchin Lytechinus variegates. Proc R Soc Lond B 2000;267:531-534.

[10] Mita M, Nakamura M. Energy metabolism of sea urchin spermatozoa: an approach based on Echinoid phylogeny. Zool Sci 1998;15:1-10.

[11] Jeong WG, Cho SM. The effects of polycyclic aromatic hydrocarbon exposure on the fertilization and larval development of the Pacific oyster, Crassostrea gigas. J Shellfish Res 2005;1:209-213.

[12] Piferrer F, Beaumont A, Falguière JC, Flajshans M, Haffray P, Colombo L. Polyploid

fish and shellfish: production, biology and applications to aquaculture for performance improvement and genetic containment. Aquac 2009;293:125-156.

[13] Guo X, Debrosse GA, Allen SK Jr. All triploid oysters (Crassostrea gigas Thunberg) produced by mating tetraploids and diploids. Aquac1996;142:149-161.

[14] Dong Q, Huang C, Tiersch T. Spermatozoal ultrastructure of diploid and tetraploid Pacific oysters. Aquac 2005;249:487-496.

[15] Dong Q, Eudeline B, Allen SK Jr., Tiersch T. Factors affecting sperm motility of tetraploid Pacific oysters. J Shellfish Res 2002;21:719-723.

[16] Song YP, Suquet M, Quéau I, Lebrun L. Setting of a procedure for experimental fertilisation of Pacific oyster (Crassostrea gigas) oocytes. Aquac 2009;287:311-314.

[17] Dong Q, Eudeline B, Huang C, Allen SK Jr, Tiersch T. Commercial-scale sperm cryopreservation of diploid and tetraploid Pacific oysters, Crassostrea gigas. Cryobiol 2005;50:1-16.

[18] Suquet M, Donval A, Labbé C, Brizard R, Le Coz JR, Quere C, Robert R,

Benabdelmouna A, Haffray P. Sperm quality in diploid and tetraploid Pacific oyster, Crassostrea gigas. In: Aquaculture Europe 09, EAS Sp Publ, pp. 525-526.

[19] Ingermann R.L. Energy metabolism and respiration in fish spermatozoa. In: Fish spermatology, Alavi SHM, Cosson J, Coward K, Rafiee G (Eds.), Alpha Science, 2008, pp. 241-266.

[20] Mita M, Fujiwara A, De Santis R, Yasumasu I. High-energy phosphate compounds in spermatozoa of the sea urchins Arbacia lixula and Paracentrotus lividus. Comp Biochem Physiol 1994;109A:269-275.

[21] Mita M, Yasumasu I. The role of external potassium ion in activation of sea urchin spermatozoa. Dev Growth Differ 1984;26:489-495.

[22] Mita M, Hino A, Yasumasu I. Effect of temperature on interaction between eggs and spermatozoa of sea urchin. Biol. Bull. 1984;166:68-77.

[23] Komaru A, Wada KT, Scarpa J. Sperm production in tetraploid mussels, Mytilus galloprovincialis. J Shellfish Res 1995;14:270.

[24] Tombes RW, Brokaw C, Shapiro BM. Creatine kinase dependant energy transport in sea urchin spermatozoa. J Biophys 1987;52:75-86.

[25] Dreanno C. Régulation de la mobilité des spermatozoïdes de turbot (Psetta maxima) et de bar (Dicentrarchus labrax) : Etude du métabolisme énergétique, du contrôle ionique, de la morphologie et du pouvoir fécondant. Thesis. Univ. Rennes 1,102pp.

[26] Levitan DR, Sewell MA, Chia FS. Kinetics of fertilization in the sea urchin

Strongylocentrotus franciscanus: Interaction of gamete dilution, age and contact time. Biol Bull 1991;181:371-378. 